Polymer Journal, Vol. 39, No. 11, pp. 1193-1198 (2007)

(C) 2007 The Society of Polymer Science, Japan

\title{
Optical Resolution of Racemic Amino Acids through DNA-Poly(4- vinylbenzyl)trimethylammonium Polyion Complex Membranes
}

\author{
Masakazu YoshiKawa,,${ }^{1, \dagger}$ Motokazu Maruhashi, ${ }^{1}$ Yuki IwAmoto, ${ }^{1}$ and Naoya OGAtA ${ }^{2}$ \\ ${ }^{1}$ Department of Biomolecular Engineering, Kyoto Institute of Technology, Matsugasaki, Kyoto 606-8585, Japan \\ ${ }^{2}$ Ogata Research Laboratory, Ltd., 1-3-1 Kashiwadai-minami, Chitose 066-0009, Japan
}

(Received June 18, 2007; Accepted August 19, 2007; Published October 2, 2007)

\begin{abstract}
Novel polyion complex membranes were prepared from DNA-Na and poly(4-vinylbenzyl)trimethylammonium chloride (PVBTMAC). The newly prepared DNA-PVBTMA polyion complex membranes showed a chiral separation ability toward racemic lysine (Lys) mixtures. The membranes transported D-Lys in preference to the corresponding L-isomer of Lys. The permselectivity toward the D-isomer reached 1.26. From transport experiments and adsorption studies, it was revealed that the permselectivity was mainly determined by diffusivity selectivity. [doi:10.1295/polymj.PJ2007080] KEY WORDS Chiral Separation / DNA / Membrane / Optical Resolution / Permselectivity / Polyion Complex / Separation /
\end{abstract}

DNA molecules carry important biological information on genetics of living things with its doublestranded structure consisting of complementary nucleic acid base pairs. ${ }^{1}$ On the other hand, DNA molecules have a huge molecular weight of over 6 millions so that DNA was reported to be one of promising natural polymers to give durable films. ${ }^{2,3}$ Since the appearance of those reports, ${ }^{2,3}$ DNA has been intensively studied in connection with optical devices, ${ }^{4-7}$ electric $^{8,9}$ or ion ${ }^{10-12}$ conductivity, ion permeation, ${ }^{13}$ capture of metal ions ${ }^{14}$ or endcrine disruptors ${ }^{14,15}$ chiral separation, ${ }^{16-18}$ and gas separation. ${ }^{19}$ Among many applications of DNA molecules, the authors focused their attention on separation membranes from DNA since membranes will play an important role in environmental and energy related processes. ${ }^{20,21}$ Chiral separation is an indispensable method in industries dealing with pharmaceuticals, agricultural chemicals, perfumes, and so forth. There are a couple of ways, such as asymmetric synthesis and resolution of racemates, to obtain optically pure enantiomers. Though asymmetric synthesis of pure enantiomers has been developed, its development is still slow. The resolution of racemates is still main methods for the production of enantiomerically pure compounds in industry. Among chiral separation technologies, such as diastereomer crystallization, preferential crystallization, chemically kinetic resolution, enzymatic kinetic resolution, chromatography, and membrane separation, the last process with membranes is perceived as economically and ecologically competitive to other conventional chiral separation methods to separate a pair of enantiomers. Membrane separation technology can be carried out continuously under mild conditions and process scale-up is relatively easy. To this end, the authors has reported chiral separation of racemic amino acids with novel membranes from polyion complex, which were prepared from DNA sodium salt (DNA$\mathrm{Na}$ and polydiallyldimethylammonium chloride (PDADMAC), because DNA is considered as a polyanion with a huge molecular weight. ${ }^{18}$ In the present study, poly(4-vinylbenzyl)trimethylammonium chloride (PVBTMAC) was adopted as a corresponding counter polycation for polyion complex formation. Novel polyion complex membranes were prepared from DNA-Na and PVBTMAC and chiral separation of racemic amino acids through those polyion complex membranes were studied.

\section{EXPERIMENTAL}

\section{Materials}

Fiberlike purified DNA sodium salt (DNA-Na) of 93\% from salmon milt (Nippon Chemical Feed Co.) was used. (4-Vinylbenzyl)trimethylammonium chloride (VBTMAC) was kindly provided by AGC SEIMI CHEMICAL CO., LTD. and used without further purification. 2,2'-Azobis[2-methyl-N-(2-hydroxyethyl)propionamide] (AMHP), D-glutamic acid (D-Glu), L-glutamic acid (L-Glu), D-lysine (D-Lys), L-lysine (L-Lys), D-phenylalanine (D-Phe), L-phenylalanine (L-Phe), $\mathrm{NaBr}, \mathrm{KCl}$ and $\mathrm{NaN}_{3}$ (fungicide) were used without further purification. Water purified with an ultrapure water system (Simpli Lab, Millipore S. A., Molsheim, France) was used.

Poly(4-vinylbenzyl)trimethylammonium chloride (PVBTMAC) was synthesized as follows: into a $270 \mathrm{~g}$ of purified $\mathrm{H}_{2} \mathrm{O}, 30.000 \mathrm{~g}\left(1.42 \times 10^{-1} \mathrm{~mol}\right)$ of

${ }^{\dagger}$ To whom correspondence should be addressed (Tel: +81-75-724-7816, Fax: +81-75-724-7800, E-mail: masahiro@kit.ac.jp). 


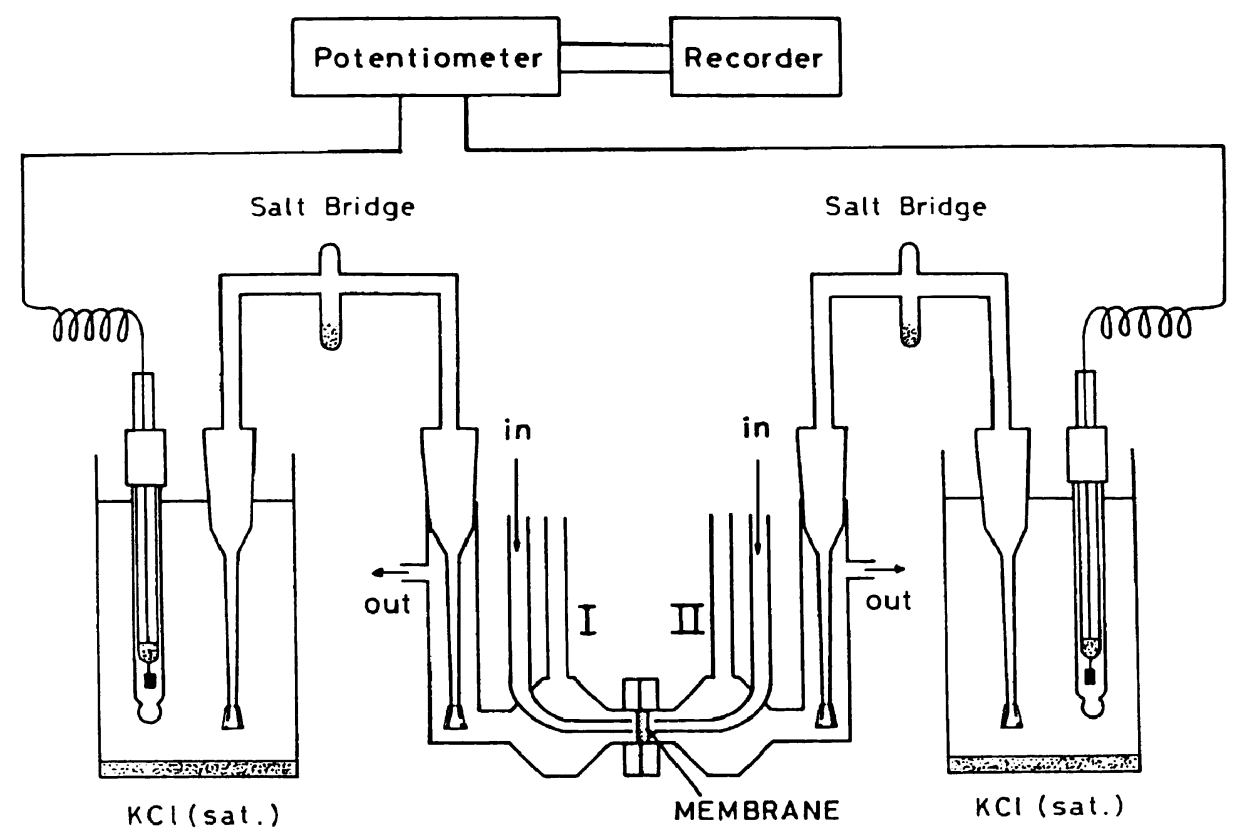

Figure 1. Schematic diagram of the cell used for the measurement of membrane potentials.

VBTMAC and $0.204 \mathrm{~g}\left(7.07 \times 10^{-4} \mathrm{~mol}\right)$ of radical initiator AMHP were dissolved. The reaction mixture was stirred at $70^{\circ} \mathrm{C}$ under a nitrogen atmosphere for $21 \mathrm{~h}$. And then the reaction mixture was heated at $80^{\circ} \mathrm{C}$ for an additional $23 \mathrm{~h}$. Aqueous PVBTMAC solution, of which concentration was nominally $10 \%$, was obtained. The polymer solution thus obtained was diluted in purified $\mathrm{H}_{2} \mathrm{O}$ to the final polymer concentration of $c a .1 .0 \%$.

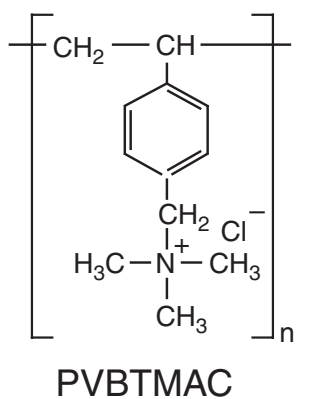

\section{Membrane Preparation}

In the present study, the composition of the base pairs of DNA-Na was not studied. Here, 662.0, the average value of base pairs of DNA-Na was adopted as an average molecular weight of the constitutional repeating unit (base pair). Polyion complex membranes were prepared from DNA-Na and PVBTMAC. DNA-PVBTMA(60/40) was prepared as follows: $10.000 \mathrm{~g}$ of $1.2 \%$ DNA-Na aqueous solution $(1.81 \times$ $10^{-4}$ mol of base pairs) and $5.118 \mathrm{~g}$ of $1.0 \%$ aqueous PVBTMAC solution $\left(2.42 \times 10^{-4} \mathrm{~mol}\right.$ of constitutional repeating units) were added to a $200.0 \mathrm{~g}$ of 20 wt. \% aqueous $\mathrm{NaBr}$ solution. The mixed solution was stirred for $1 \mathrm{~h}$ at ambient temperature. The mixture was poured into the ultrafiltration cell (Model
8400 , Amicon). The mixture was filtered with a regenerated cellulose UF membrane (diameter, $76 \mathrm{~mm}$ : Amicon) with a nominal molecular weight limit of 1,000 at the operation pressure of $0.20 \mathrm{MPa}$. The retentate was thoroughly washed with pure $\mathrm{H}_{2} \mathrm{O}$ at the operation pressure of $0.20 \mathrm{MPa}$ so that the $\mathrm{NaBr}$ concentration in the filtrate (the permeate) could reach $2.0 \times 10^{-3} \mathrm{~mol} \mathrm{dm}^{-3}$, which was confirmed by conductimetry. DNA-PVBTMA(50/50) membrane was prepared from $10.000 \mathrm{~g}$ of $1.2 \%$ DNA-Na aqueous solution and $7.678 \mathrm{~g}$ of $1.0 \%$ aqueous PVBTMAC solution $\left(3.63 \times 10^{-4} \mathrm{~mol}\right.$ of constitutional repeating units) and DNA-PVBTMA(40/60) from $10.000 \mathrm{~g}$ of $1.2 \%$ DNA-Na aqueous solution and $11.516 \mathrm{~g}$ of $1.0 \%$ aqueous PVBTMAC solution $\left(5.44 \times 10^{-4} \mathrm{~mol}\right.$ of constitutional repeating units). The polyion complex membrane thus obtained could not be removed from the regenerated cellulose UF membrane.

\section{Membrane Potential Measurement}

The membrane potential was measured by using the standard laboratory set-up. ${ }^{22}$ The schematic diagram of the apparatus used for measuring membrane potentials is shown in Figure 1. The electromotive force which across between the bulk solution was conducted by saturated $\mathrm{KCl}$ bridge and calomel electrodes and measured by a potentiometer, Electrometer HE-106 (Hokuto Denko Co.). The bulk solutions of both sides of the membrane were stirred by the flow of themselves.

The anion transport number $\left(t_{-}\right)$of the membrane was determined by the concentration-membrane potential $\varepsilon\left(E_{\mathrm{I}}-E_{\mathrm{II}}\right)$ at $25^{\circ} \mathrm{C}$ with an aqueous solution of $\mathrm{KCl}$ using ${ }^{23}$ 
Optical Resolution through DNA-Polyion Complex Membranes

Table I. Membrane potential and transport numbers for $\mathrm{K}^{+}$and $\mathrm{Cl}^{-}$in DNA-PVBTMA polyion complex membranes

\begin{tabular}{lccccc}
\hline & \multicolumn{2}{c}{ membrane potential $/ \mathrm{mV}$} & & \multicolumn{2}{c}{ transport number } \\
\cline { 2 - 3 } \cline { 5 - 6 } & $0.2 \mathrm{~mol} \mathrm{dm}^{-3}$ side & $0.1 \mathrm{~mol} \mathrm{dm}^{-3}$ side & & $\mathrm{t}\left(\mathrm{K}^{+}\right)$ & $\mathrm{t}\left(\mathrm{Cl}^{-}\right)$ \\
\hline DNA-PVBTMA (60/40) & 0 & 0.50 & & 0.514 & 0.486 \\
DNA-PVBTMA (50/50) & 0.07 & 0 & & 0.498 & 0.502 \\
DNA-PVBTMA (40/60) & 4.60 & 0 & 0.371 & 0.629 \\
\hline
\end{tabular}

$$
\varepsilon=E_{\mathrm{I}}-E_{\mathrm{II}}=\left(2 t_{-}-1\right)(R T / F) \ln \left(C_{\mathrm{I}} / C_{\mathrm{II}}\right)
$$

where $C_{\mathrm{I}}$ and $C_{\mathrm{II}}$ represent the concentration of the solution on either side of the membrane $(0.200$ and $0.100 \mathrm{~mol} \mathrm{dm}^{-3}$, respectively). $F$ is the Faraday constant, $R$ is the gas constant, and $T$ means the absolute temperature.

\section{Membrane Performance Study}

Enantioselective permeation of racemic amino acids and adsorption selectivity of the membrane toward racemic amino acids were carried out by following the procedures described in the previous paper. ${ }^{24}$ All experiments were carried out at $40^{\circ} \mathrm{C}$.

The permselecvtivity $\alpha_{\mathrm{D} / \mathrm{L}}$ is defined as the flux ratio $\mathrm{J}_{\mathrm{D}} / \mathrm{J}_{\mathrm{L}}$ divided by the concentration ratio of racemic amino acids [D-AA]/[L-AA]:

$$
\alpha_{\mathrm{D} / \mathrm{L}}=\left(\mathrm{J}_{\mathrm{D}} / \mathrm{J}_{\mathrm{L}}\right) /([\mathrm{D}-\mathrm{AA}] /[\mathrm{L}-\mathrm{AA}])
$$

The adsorption selectivity $\mathrm{S}_{\mathrm{A}(\mathrm{D} / \mathrm{L})}$ is defined as:

$$
\mathrm{S}_{\mathrm{A}(\mathrm{D} / \mathrm{L})}=((\mathrm{D}-\mathrm{AA}) /(\mathrm{L}-\mathrm{AA})) /([\mathrm{D}-\mathrm{AA}] /[\mathrm{L}-\mathrm{AA}])
$$

where (D-AA) and (L-AA) are the amounts of racemic amino acids adsorbed in the membrane and [D$\mathrm{AA}]$ and $[\mathrm{L}-\mathrm{AA}]$ are the concentrations in the solution after equilibrium has been reached.

\section{RESULTS AND DISCUSSION}

\section{Characterization of Polyion Complex Membranes}

Before studying chiral separation of racemic amino acids with those DNA-PVBTMA polyion complex membranes thus prepared, the membrane potentials for those three types of membranes were measured to characterize them. Using observed membrane potentials, transport numbers of $\mathrm{K}^{+}$and $\mathrm{Cl}^{-}$in the polyion complex membranes were determined and those calculated values are summarized in Table I together with the corresponding membrane potentials. The transport numbers of $\mathrm{K}^{+}$and $\mathrm{Cl}^{-}$in aqueous solution were reported to be around 0.4905 and 0.5095 , respectively. ${ }^{25}$ The transport number of $\mathrm{K}^{+}$for DNAPVBTMA(60/40) membrane was determined to be 0.514 , which was slightly higher than that in bulk aqueous solution of 0.4905 . From this, it was revealed that the amount of fixed anionic charge site was more than that of cationic charged one. This coincides with the fact that DNA-PVBTMA(60/40) nominally consisted of $1.81 \times 10^{-4} \mathrm{~mol}$ of base pairs and $2.42 \times$ $10^{-4} \mathrm{~mol}$ of PVBTMAC constitutional repeating units. The transport number of $\mathrm{K}^{+}$and $\mathrm{Cl}^{-}$for DNA-PVBTMA(50/50) membrane were close to those in aqueous solution. This leads to the conclusion that DNA-PVBTMA(50/50) membrane was electrically neutralized, which can be supported by the composition of polyion complex membrane. On the other hand, the transport number of $\mathrm{K}^{+}$for DNAPVBTMA(40/60) membrane was determined to be 0.371 , which was much more lower than that in aqueous solution. This revealed that there was excess amount of cationic charges in the DNAPVBTMA(40/60) membrane. This also coincides with the membrane preparation process that it nominally consisted of $1.81 \times 10^{-4} \mathrm{~mol}$ of base pairs and $5.44 \times 10^{-4} \mathrm{~mol}$ of PVBTMAC constitutional repeating units.

Chiral Separation of Racemic Amino Acids with Polyion Complex Membranes

In the present study, three types of racemic amino acids were adopted as model racemic mixtures, such as racemic glutamic acids (Glu's), which have very polar anionic side chains, racemic lysines (Lys's) with very polar cationic side chains, and racemic phenylalanines (Phe's), having aromatic side chains. Time transport curves for those three types of racemic amino acids through DNA-PVBTMA(60/40) membrane are shown in Figure 2, those through DNA$\operatorname{PVBTMA}(50 / 50)$ membrane in Figure 3, and those through DNA-PVBTMA(40/60) in Figure 4, respectively.

D-Lys was transported in preference to the corresponding L-isomer through negatively charged DNAPVBTMA(60/40) and positively charged DNAPVBTMA(40/60) membranes, while chiral separation of racemic Lys's through the electrically neutral DNA-PVBTMA(50/50) membrane was hardly observed. The electrically neutral DNA-PDADMA polyion complex membrane transported the L-isomer of tryptophan or phenylalanine in preference to the corresponding D-isomer in the previous study. ${ }^{18}$ As for other racemic amino acids, such as racemic Glu's and Phe's, optical resolution was hardly observed in the present study. Transport experiments for three 
DNA-PVBTMA(60/40)
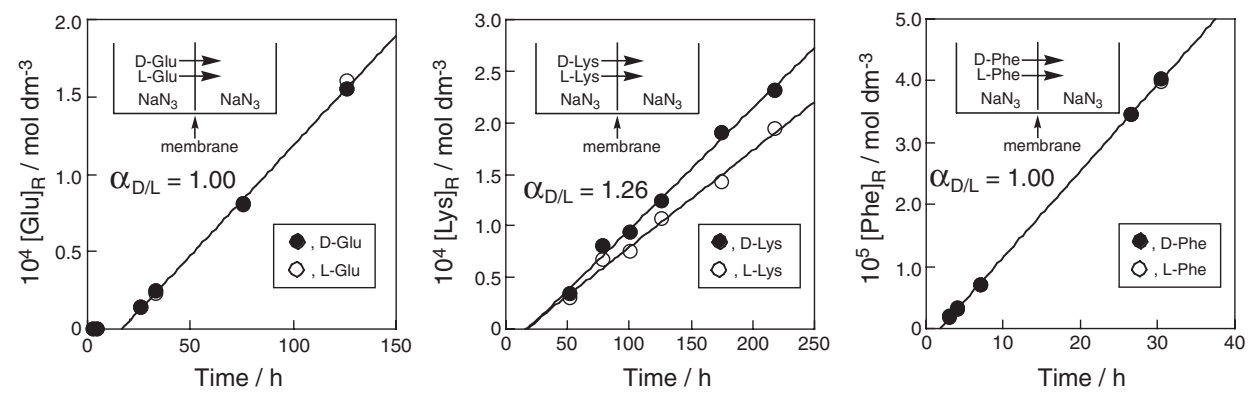

Figure 2. Time-transport curves of three types of racemic amino acids through DNA-PVBTMA $(60 / 40)$ membranes at $40^{\circ} \mathrm{C}$.

\section{DNA-PVBTMA(50/50)}
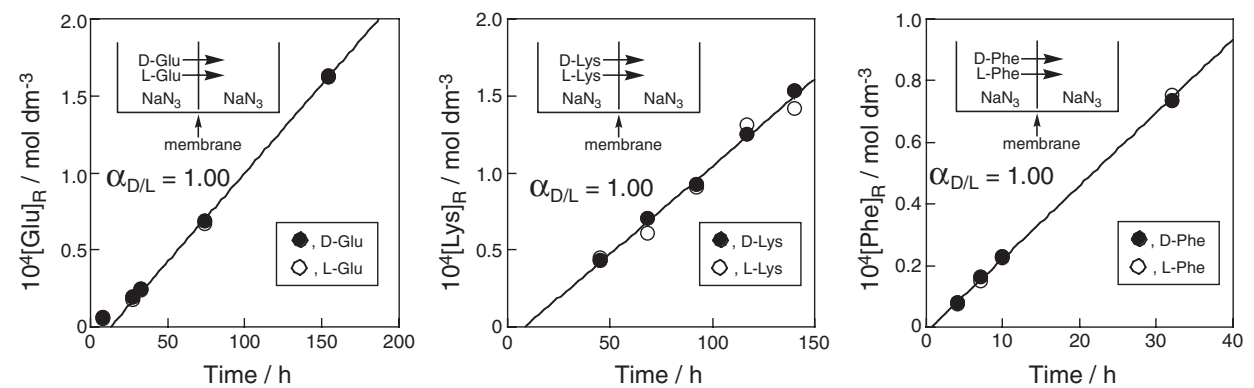

Figure 3. Time-transport curves of three types of racemic amino acids through DNA-PVBTMA $(50 / 50)$ membranes at $40^{\circ} \mathrm{C}$.

DNA-PVBTMA(40/60)
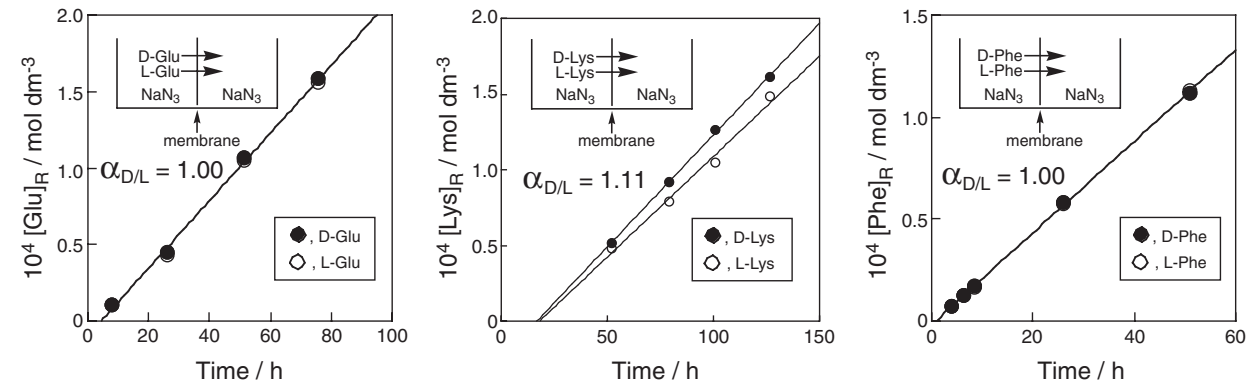

Figure 4. Time-transport curves of three types of racemic amino acids through DNA-PVBTMA $(40 / 60)$ membranes at $40{ }^{\circ} \mathrm{C}$.

types of racemic amino acids through those three types of polyion complex membranes are summarized in Table II. Permselectivities toward D-Lys for DNAPVBTMA(60/40) and DNA-PVBTMA(40/60) membranes were determined to be 1.26 and 1.11 , respectively.

In order to elucidate the mechanism for the expression of chiral separation, adsorption selectivities of those three types of membranes toward racemic amino acids were studied. The results of adsorption experiments are summarized in Table III. In the table, the amount of amino acid adsorbed in the membrane is given as a relative amount to total charged site or excess ionic site in each membrane. In the present study, the surface of those three types of membranes seemed to be slightly swollen compared to adsorption selec- tivity experiments of DNA-PDADMA polyion complex membranes. ${ }^{18}$ Among those data, L-Lys was remarkably adsorbed in DNA-PVBTMA(60/40) and DNA-PVBTMA(40/60) membranes in preference to D-Lys, and those adsorption selectivities were determined to be 0.33 and 0.39 , respectively. Those adsorption selectivities are converted to be 3.03 and 2.56 , respectively, if they are given toward L-isomer $\left(\mathrm{S}_{\mathrm{A}(\mathrm{L} / \mathrm{D})}\right)$. In the previous study, DNA-PDADMA polyion complex membrane also showed adsorption selectivity toward the L-isomer, ${ }^{18}$ and those values were reported to be 1.24 for L-tryptophan and 1.17 for L-Phe, respectively. Compared to adsorption selectivities of L-Lys for DNA-PVBTMA(60/40) and DNA-PVBTMA(40/60) membranes, other adsorption selectivities were close to unity. In the present study, 
Optical Resolution through DNA-Polyion Complex Membranes

Table II. Transport of racemic amino acids through DNA-PVBTMA polyion complex membranes

\begin{tabular}{ccccc}
\hline Membrane & Amino Acid & $10^{8} \mathrm{~J}_{\mathrm{D}} / \mathrm{mol} \mathrm{cm}^{-2} \mathrm{~h}^{-1}$ & $10^{8} \mathrm{~J}_{\mathrm{L}} / \mathrm{mol} \mathrm{cm}^{-2} \mathrm{~h}^{-1}$ & $\alpha_{\mathrm{D} / \mathrm{L}}$ \\
\hline DNA-PVBTMA(60/40) & Phe & 1.87 & 1.87 & 1.00 \\
DNA-PVBTMA(60/40) & Glu & 1.90 & 1.25 & 1.00 \\
DNA-PVBTMA(60/40) & Lys & 1.57 & 3.17 & 1.26 \\
DNA-PVBTMA(50/50) & Phe & 3.17 & 1.47 & 1.00 \\
DNA-PVBTMA(50/50) & Glu & 1.47 & 1.51 & 1.00 \\
DNA-PVBTMA(50/50) & Lys & 1.51 & & 1.00 \\
DNA-PVBTMA(40/60) & & & 3.00 & 1.00 \\
DNA-PVBTMA(40/60) & Phe & 3.00 & 2.95 & 1.00 \\
DNA-PVBTMA(40/60) & Glu & 2.95 & 1.77 & 1.11 \\
\hline
\end{tabular}

Table III. Adsorption selectivities of DNA-PVBTMA polyion complex membranes toward racemic amino acids

\begin{tabular}{|c|c|c|c|c|c|c|c|c|}
\hline \multirow{2}{*}{ Membrane } & \multirow{2}{*}{$\begin{array}{l}\text { Amino } \\
\text { Acid }\end{array}$} & \multirow{2}{*}{$\frac{10^{2}(\mathrm{D}-\mathrm{AA})}{\text { (anionic site) }}$} & \multirow{2}{*}{$\frac{10^{2}(\mathrm{~L}-\mathrm{AA})}{(\text { anionic site })}$} & \multirow{2}{*}{$\frac{10^{2}(\mathrm{D}-\mathrm{AA})}{\text { (cationic site) }}$} & \multirow{2}{*}{$\frac{10^{2}(\mathrm{~L}-\mathrm{AA})}{\text { (cationic site) }}$} & \multirow{2}{*}{$\frac{10^{2}(\mathrm{D}-\mathrm{AA})}{(\text { excess ionic site })}$} & \multirow{2}{*}{$\frac{10^{2}(\mathrm{~L}-\mathrm{AA})}{(\text { excess ionic site })}$} & \multirow{2}{*}{$\mathrm{S}_{\mathrm{A}(\mathrm{D} / \mathrm{L})}$} \\
\hline & & & & & & & & \\
\hline DNA-PVBTMA(60/40) & Glu & 0.090 & 0.075 & 0.135 & 0.113 & 0.270 & 0.226 & 1.19 \\
\hline DNA-PVBTMA(60/40) & Lys & 0.488 & 1.395 & 0.733 & 2.093 & 1.465 & 4.185 & 0.33 \\
\hline DNA-PVBTMA(60/40) & Phe & 0.231 & 0.218 & 0.347 & 0.327 & 0.693 & 0.654 & 1.06 \\
\hline DNA-PVBTMA(50/50) & Glu & 0.785 & 0.862 & 0.785 & 0.862 & - & - & 0.91 \\
\hline DNA-PVBTMA(50/50) & Lys & 0.519 & 0.595 & 0.519 & 0.595 & - & - & 0.87 \\
\hline DNA-PVBTMA(50/50) & Phe & 0.085 & 0.094 & 0.085 & 0.094 & - & - & 0.90 \\
\hline DNA-PVBTMA(40/60) & Glu & 0.314 & 0.291 & 0.209 & 0.194 & 0.627 & 0.582 & 1.08 \\
\hline DNA-PVBTMA(40/60) & Lys & 0.617 & 1.519 & 0.411 & 1.012 & 1.234 & 3.037 & 0.39 \\
\hline DNA-PVBTMA(40/60) & Phe & 0.199 & 0.217 & 0.133 & 0.145 & 0.398 & 0.435 & 0.91 \\
\hline
\end{tabular}

L-Lys, which is thought to be positively charged under experimental conditions, was preferentially incorporated into two types of DNA-polyion complex membranes, such as that with excess anionic charge site and that positively charged. If Coulombic interaction were the dominant factor for chiral recognition, L-Lys would not be incorporated into DNAPVBTMA(40/60) membrane, which was positively charged. However, L-Lys was observed to be selectively incorporated into DNA-PVBTMA(40/60) membrane. This revealed that Coulombic interaction between L-Lys and charged site in a polyion complex membrane might not be the dominant factor for the present adsorption selectivity. The interaction between amino acids and 2-deoxyribose and that between amino acids and bases are enumerated as the interactions for the chiral recognition. At least, it can be said that similar site works as a chiral recognition in negatively charged DNA-PVBTMA and positively charged DNA-PVBTMA polyion complex membranes to discriminate L-Lys and the corresponding D-Lys. However, at the moment, we cannot specify the precise interaction mode for chiral recognition.

The diffusivity selectivity $\left(\mathrm{S}_{\mathrm{D}(\mathrm{D} / \mathrm{L})}=\mathrm{D}_{\mathrm{D}} / \mathrm{D}_{\mathrm{L}}\right.$, where $D_{D}$ and $D_{L}$ are the diffusion coefficients of the D-isomer and the L-isomer, rerspectively) for each reacemic mixtures can be determined using permselectivity $\left(\alpha_{\mathrm{D} / \mathrm{L}}\right)$ and adsorption selectivity $\left(\mathrm{S}_{\mathrm{A}(\mathrm{D} / \mathrm{L})}\right)$. The estimated diffusivity selectivities are summarized in Table IV together with permselectivities and adsorption selectivities. Results summarized in Table IV revealed that the chiral separation was mainly governed by the diffusivity selectivity toward the target molecule. Contrary to adsorption selectivity, D-Lys,

Table IV. Results of chiral separation with DNA-PVBTMA polyion complex membranes

\begin{tabular}{ccccc}
\hline Membrane & Amino Acid & $\alpha_{\mathrm{D} / \mathrm{L}}$ & $\mathrm{S}_{\mathrm{A}(\mathrm{D} / \mathrm{L})}$ & $\mathrm{S}_{\mathrm{D}(\mathrm{D} / \mathrm{L})}$ \\
\hline DNA-PVBTMA(60/40) & Glu & 1.00 & 1.19 & 0.84 \\
DNA-PVBTMA(60/40) & Lys & 1.26 & 0.33 & 3.82 \\
DNA-PVBTMA(60/40) & Phe & 1.00 & 1.06 & 0.94 \\
& & & & \\
DNA-PVBTMA(50/50) & Glu & 1.00 & 0.91 & 1.10 \\
DNA-PVBTMA(50/50) & Lys & 1.00 & 0.87 & 1.15 \\
DNA-PVBTMA(50/50) & Phe & 1.00 & 0.90 & 1.11 \\
& & & & \\
DNA-PVBTMA(40/60) & Glu & 1.00 & 1.08 & 0.93 \\
DNA-PVBTMA(40/60) & Lys & 1.11 & 0.39 & 2.85 \\
DNA-PVBTMA(40/60) & Phe & 1.00 & 0.91 & 1.10 \\
\hline
\end{tabular}

$\mathrm{S}_{\mathrm{D}(\mathrm{D} / \mathrm{L})}=\alpha_{\mathrm{D} / \mathrm{L}} / \mathrm{S}_{\mathrm{A}(\mathrm{D} / \mathrm{L})}$ 
which was not preferentially incorporated into the membrane, was selectively transported through DNAPVBTMA(60/40) and DNA-PVBTMA(40/60) membranes. In other words, retarded transport of preferentially adsorbed permeant was observed. This might be due to relatively strong interaction between the preferentially incorporated enantiomer and the membrane. Such phenomena were often observed in chiral separation. ${ }^{24,26-29}$

In the future, it is necessary to suppress the swelling of polyion complex membranes to enhance their permselectivity. Such an approach is currently under investigation in our laboratory.

\section{CONCLUSIONS}

Novel polyion complex membranes were prepared from DNA-Na and poly(4-vinylbenzyl)trimethylammonium chloride (PVBTMAC). The newly prepared DNA-PVBTMA polyion complex membranes showed a chiral separation ability toward racemic lysine (Lys) mixtures. The membranes transported D-Lys in preference to the corresponding L-Lys. The permselectivity toward the D-isomer reached 1.26. From transport experiments and adsorption studies, it was revealed that the permselectivity was mainly governed by diffusivity selectivity. The present results suggest that polyion complex membranes, consisting of DNA as a polyanion, have potential to separate racemic enantiomers. The present results indicate the great possibility for practical applications.

\section{REFERENCES}

1. D. Voet and J. G. Voet, in "Biochemistry," Wiley, New York, 1990.

2. K. Ijiro and Y. Okahata, J. Chem. Soc., Chem. Commun., 1339 (1992).

3. K. Tanaka and Y. Okahata, J. Am. Chem. Soc., 118, 10679 (1996).

4. Y. Kawabe, L. Wang, S. Horinouchi, and N. Ogata, Adv. Mater., 12, 1281 (2000).

5. L. Wang, J. Yoshida, and N. Ogata, Chem. Mater., 13, 1273 (2001).
6. Y. Kawabe, L. Wang, T. Nakamura, and N. Ogata, Appl. Phys. Lett., 81, 1372 (2002).

7. N. Ogata, Kobunshi Ronbunshu, 61, 22 (2004).

8. Y. Okahata, T. Kobayashi, K. Tanaka, and M. Shimomura, J. Am. Chem. Soc., 120, 6165 (1998).

9. J. Won, S. K. Chae, J. H. Kim, H. H. Park, Y. S. Kang, and H. S. Kim, J. Membr. Sci., 249, 113 (2005).

10. H. Ohno and N. Takizawa, Chem. Lett., 642 (2000).

11. H. Ohno and N. Nishimura, J. Electrocem. Soc., 148, E168 (2001).

12. N. Nishimura and H. Ohno, J. Mater. Chem., 12, 2299 (2002).

13. V. Misoska, W. E. Price, S. F. Ralph, G. G. Wallace, and N. Ogata, Synth. Met., 123, 279 (2001).

14. M. Yamada, K. Kato, K. Shindo, M. Nomizu, M. Haruki, N. Sakairi, K. Ohkawa, H. Yamamoto, and N. Nishi, Biomaterials, 22, 3121 (2001).

15. M. Yamada, K. Kato, M. Nomizu, N. Sakairi, K. Ohkawa, H. Yamamoto, and N. Nishi, Chem. Eur. J., 8, 1407 (2002).

16. A. Higuchi, H. Yomogida, B. O. Yoon, T. Kojima, M. Hara, S. Maniwa, and M. Saitoh, J. Membr. Sci., 205, 203 (2002).

17. A. Higuchi, Y. Higuchi, K. Furuta, B. O. Yoon, M. Hara, S. Maniwa, M. Saitoh, and K. Sanui, J. Membr. Sci., 221, 207 (2003).

18. M. Yoshikawa, M. Maruhashi, Y. Iwamoto, and N. Ogata, Macromol. Symp. 249-250, 557 (2007).

19. T. Matsuura, T. Sada, M. Yoshikawa, and N. Ogata, Membrane, 31, 281 (2006).

20. "Membrane Handbook," W. Ho and K. Sirkar, Ed., Chapman \& Hall, New York, 1992.

21. R. W. Baker, in "Membrane Technology and Applications," 2nd. ed., Wiley, West Sussex, 2004.

22. M. Yoshikawa, T. Yukoshi, K. Sanui, and N. Ogata, J. Appl. Polym. Sci., 33, 2369 (1987).

23. S. Itoi, Membrane, 6, 185 (1981).

24. M. Yoshikawa and J. Izumi, Macromol. Biosci., 3, 487 (2003).

25. T. Hanai, in "Maku to Ion," Kagaku Dojin, Kyoto, 1978.

26. T. Kakuchi, T. Takaoka, and K. Yokota, Polym. J., 22, 199 (1990).

27. T. Masawaki, M. Sasai, and S. Tone, J. Chem. Eng. Jpn, 25, 33 (1992).

28. T. Aoki, S. Tomizawa, and E. Oikawa, J. Membr. Sci., 99, 117 (1995).

29. S. Tone, T. Masawaki, and K. Eguchi, J. Membr. Sci., 118, 31 (1996). 